\title{
Duodenal Malt Lymphoma Developed in 1 Year
}

\section{Ferdane Sapmaz, $M D^{1 *}$, Evrim Kahramanoğlu Aksoy, MD ${ }^{1}$, Muhammed Yener Akpınar, MD ${ }^{1}$, Ayşegül Erdem $^{2}$ Metin Uzman, MD ${ }^{1}$, and Yusuf Sedar Sakin ${ }^{3}$}

${ }^{1}$ Department of Gastroenterology, Kecioren Research and Training Hospital, Ankara, Turkey

${ }^{2}$ Department of Pathology, Kecioren Research and Training Hospital, Ankara, Turkey

${ }^{3}$ Gastroenterology Department, Gülhane Training and Research Hospital, Turkey

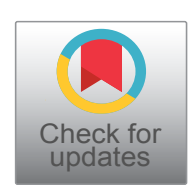

*Corresponding author: Ferdane Sapmaz, MD, Department of Gastroenterology, Kecioren Research and Training Hospital, Ankara, 06380, Turkey, Tel: +90-505-3576184, Fax: +90-312-356-90-03

\begin{abstract}
Intestinal MALT lymphoma is a very rare neoplasm and there is limited data about clinical and pathological characteristics. They can become visible in a very short time. A 47-year-old woman was referred to our department because of epigastric pain. Gastroduodenoscopy revealed an irregular mucosal nodular lesion with ulceration extending from the bulb to the second portion of the duodenum. Endoscopic findings were normal about one year ago. The pathology spesiemens show that; duodenal biopsy revealed atypical lymphoid infiltration with centrocyte-like morphology; immunophenotypic investigation was positive for CD20(+) and negative for CD3 and CD10. In gastric biopsies Helicobacter pylori was positive. We successfully eradicated $H$. pylori but did not see signs of remission. Here in we report a case of duodenal MALT Iymhoma that was visible in one year and was resistant to Helicobacter pylori eradication.
\end{abstract}

\section{Introduction}

Primary MALT lymphoma represents approximately $8 \%$ of the total number of non-Hodgkin lymphoma [1]. GI MALT lymphomas usually occur in the stomach, sometimes the jejunum, the ileum, and rarely the duodenum [2]. The stomach is the most common site of localization. The role of Helicobacter pylori in the pathogenesis of gastric MALT lymphoma is a well known issue [3]. H. pylori eradication is the first line treatment for gastric MALT lymphoma.

Intestinal MALT Iymphoma is a very rare neoplasm and there is limited data about clinical and pathological characteristics. In some cases, endoscopic appearance is similar to adenocarcinoma. However, lymphomas may show different characteristics than adenocarcinoma with doubling times. They can become visible in a very short time.

Also the optimal treatment of duodenal MALT lymphomas has not been standardized yet. In duodenal lymphomas, there are contradictory outcomes of $\mathrm{He}$ licobacter pylori treatment. In a few cases, it has been shown that duodenal MALT lymphoma can be treated with Helicobacter pylori eradication.

In this report, we aimed to present a case of duodenal MALT lymhoma that was visible in one year and was resistant to Helicobacter pylori eradication.

\section{Case}

A 47-year-old female patient was admitted to our clinic with epigastric pain. There was no history of any previous disease. Her physical examination, routine hematology, and biochemistry tests were normal. It was learned that the patient underwent endoscopy 1 years ago. The endoscopy did not reveal any findings except pangastrit.

A gastroduodenoscopy performed again. In gastroduodenoscopy, apical duodenum was observed edematous, fragile and granular; multiple small ulcerated and vegetan lesions were seen. There were no gastric or esophageal lesions. Multiple duodenal and gastric biopsies were taken during endoscopy. Histology of the duodenal lesion was compatible with MALT lymphoma (Figure 1 and Figure 2). The pathology spesiemens show that; duodenal biopsy revealed atypical lymphoid infil- 


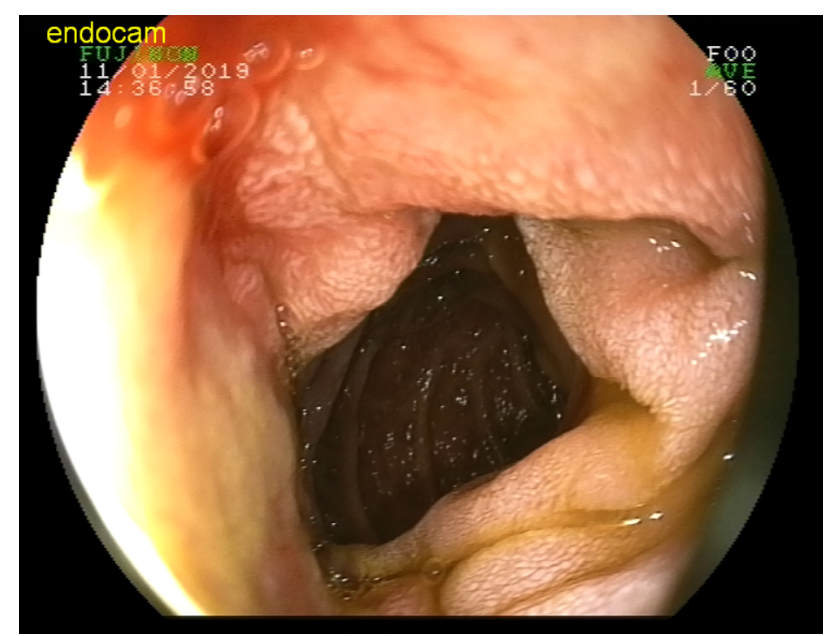

Figure 1: MALT lympoma in duodenum.

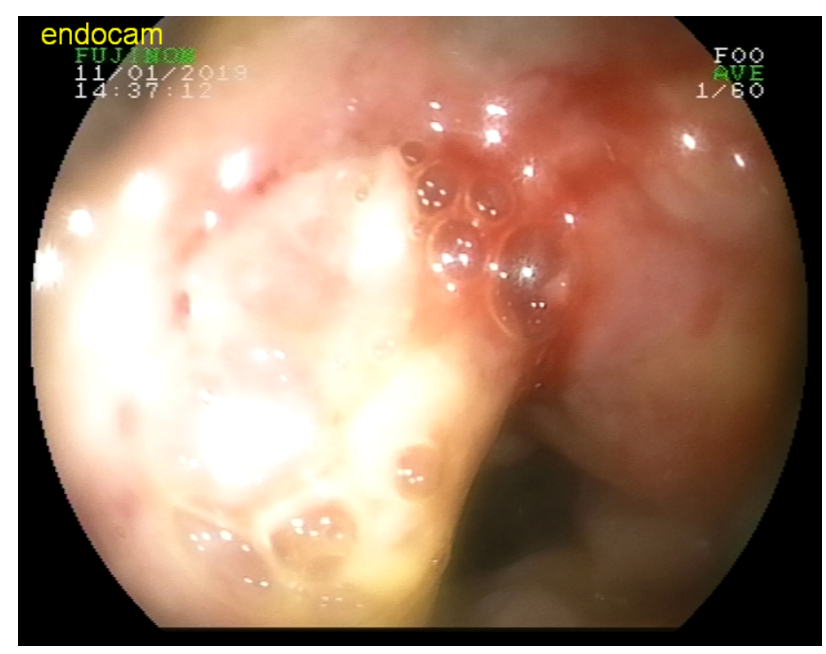

Figure 2: MALT lympoma in duodenum.

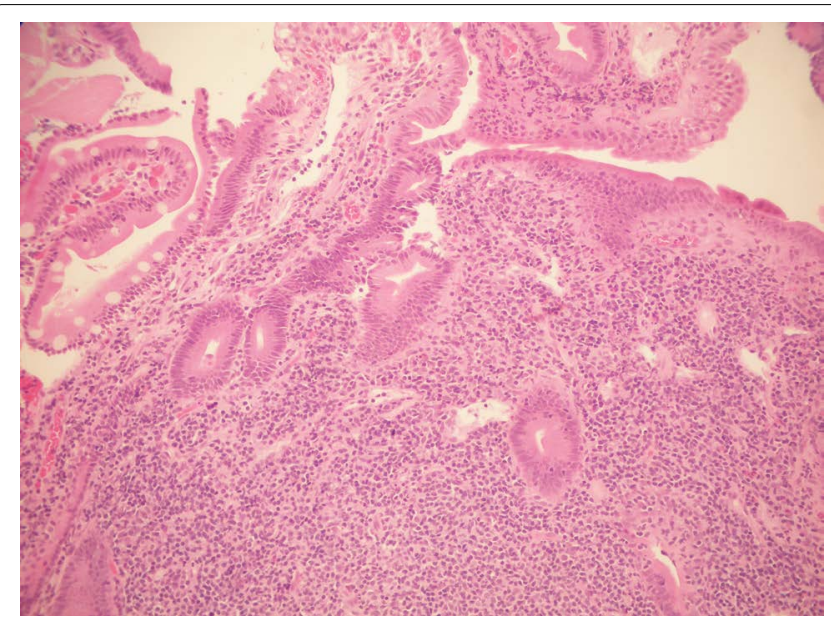

Figure 3: The tumor. The submucosa is filled with small $B$ lymphocytes with conspicuous nuclei. H\&E, × 10 .

tration with centrocyte-like morphology (Figure 3); immunophenotypic investigation was positive for CD 20(+) and negative for CD3 and CD10 (Figure 4 and Figure 5). In gastric biopsies Helicobacter pylori was positive. In bone marrow biopsy, mild hypercellularity was seen and infiltration was not detected. Her colonoscopy and CT scan was normal.

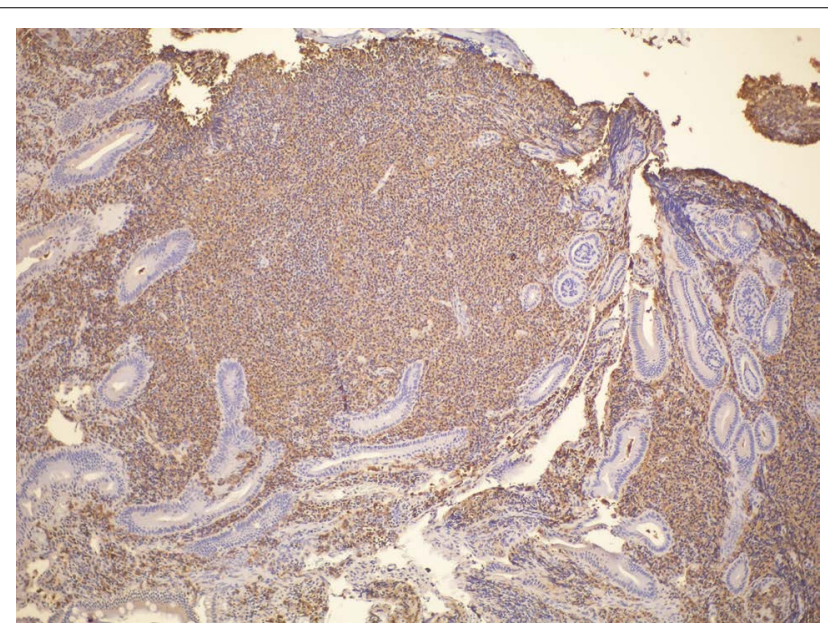

Figure 4: The tumor. Submucosal B cells stain positive for CD 20; those cells are also CD5-, CD10- and CD23negative.

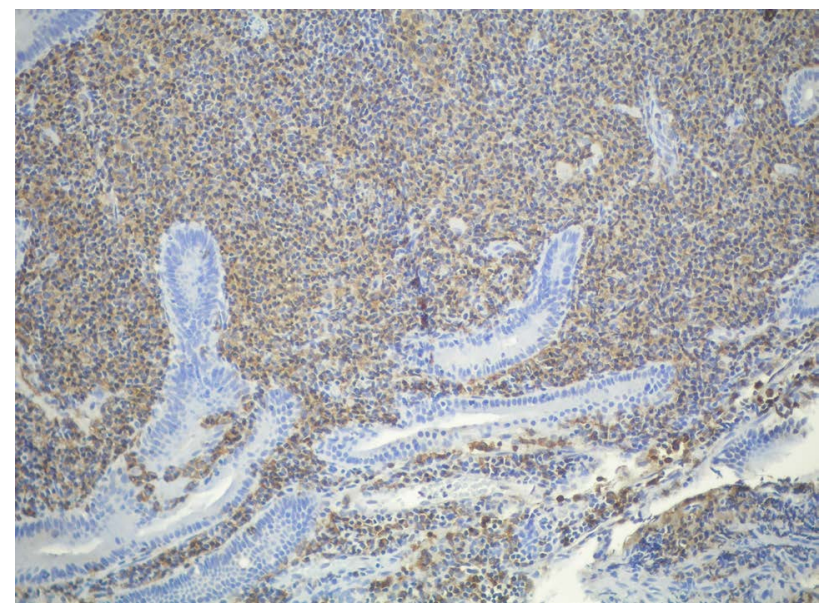

Figure 5: The tumor. Submucosal B cells stain positive for CD20; those cells are also CD5-, CD10- and CD23negative.

Diagnosis of MALT lymphoma of the small intestine was considered, and firstly we decided to Helicobacter pylori eradication. For this treatment we planned; pantoprazol $40 \mathrm{mg} 2 \times 1$, tetrasiclin $500 \mathrm{mg} 4 \times 1$, metronidazol $500 \mathrm{mg} 3 \times 1$ and bizmuth subsalisilat $4 \times 1$ for 14 days.

Control gastroduodenoscopy 4 week after treatment, no change in lesions was observed. After this treatment the patient subsequently underwent cyclophosphamide, hydroxydaunorubicin, oncovin, prednisolone, and rituximab chemotherapy. The patient is still being followed.

\section{Discussion}

Although MALT lymphoma is usually a tumor of interest to the gastrointestinal tract, it can also be seen in organs such as salivary glands, thyroid gland, lung, and skin [4]. Among these sites, MALT lymphoma arising from the gastric mucosa is the most frequently reported, accounting for more than $75 \%$ of gastrointestinal 
tract lymphomas [5]. In contrast, MALT Iymphoma of the duodenum is very rare.

The lymphomas have shorter doubling times compared to adenocarcinomas [6]. In the literature, there is no clear information about the time of tumor doubling of MALT lymphomas. In our case, although duodenal endoscopy findings were completely normal 1 year ago, within 1 year it had resulted in a rather large mass formation. This time is too short for the adenocarcinoma to become visible. Therefore, in patients with persistent symptoms, it is possible to repeat the endoscopy in shorter periods.

The relationship between $H$. pylori infection and gastric MALT lymphoma is well established, therefore $H$. pylori eradication is recommended as the first-step treatment for gastric MALT lymphoma, if there has been confirmation of $H$. pylori infection [7]. In contrast to gastric MALT lymphoma, the relationship between duodenal MALT lymphoma and $H$. pylori infection has not been established. For duodenal MALT Iymphoma, $H$. pylori eradication may or may not, lead to lymphoma regression [8]. Here, $H$. pylori eradication did not cure duodenal MALT Iymphoma.

In our case, as the first-line treatment, we aimed at the eradication of Helicobacter pylori. After $H$. pylori treatment, control endoscopy was performed and eradication was shown as pathological. Unfortunately, eradication did not lead to treatment of the mass.

When the patient did not benefit from the treatment, chemotherapy was started.

The duodenal MALT Iymphomas still do not have a standard treatment method. In very few cases, eradica- tion alone has therapeutic properties.

\section{Conflict of Interest}

None.

\section{References}

1. Wang HH, Lin JT, Chiu CC, Chiang IP, Wu MS, et al. (1995) Endoscopic features of mucosa-associated lymphoid tissue lymphoma of the duodenum. Gastrointest Endosc 41: 258261.

2. Radaszkiewicz T, Dragosics B, Bauer P (1992) Gastrointestinal malignant lymphomas of the mucosa-assiciated lymphoid tissue: factors relevant to prognosis. Gastroenterology 102: 1628-1638.

3. Kim JS, Jung HC, Shin KH, Song IS, Kim CW, et al. (1999) Eradication of Helicobacter pylori infection did not lead to cure of duodenal mucosa-associated lymphoid tissue lymphoma. Scand J Gastroenterol 34: 215-218.

4. Nakamura $S$, Matsumoto $T$, lida M, Yao T, Tsuneyoshi M (2003) Primary gastrointestinal lymphoma in Japan: A clinicopathologic analysis of 455 patients with special reference to its time trends. Cancer 97: 2462-2473.

5. Saito T, Toyoda H, Yamaguchi M, Nakamura T, Nakamura $S$, et al. (2005) Ileocolonic lymphomas: A series of 16 cases. Endoscopy 37: 466-469.

6. Craig VJ, Cogliatti SB, Arnold I, Gerke C, Balandat JE, et al. (2010) B-cell receptor signaling and CD40 ligand-independent $T$ cell help cooperate in Helicobacter-induced MALT lymphomagenesis. Leukemia 24: 1186-1196.

7. Saluja SS, Kalayarasan R, Mishra PK, Saran RK (2012) Duodenal MALToma with gastric outlet obstruction. case report and review of literature. J Gastrointest Cancer 43: 329-331.

8. Usmani SZ, Ding L, Abu-Rashed AH, Saleh HA (2007) Duodenal MALT lymphoma presenting with obstructive jaundice: Report of a case and review of the literature. J Gastrointest Cancer 38: 28-31. 